DOI: $10.17805 / z p u .2016 .1 .18$

\title{
Риски выбора стратегии развития российской промышленности
}

\author{
Е. А. ПАНФИЛОВА
}

(МОСКОВСКИЙ ГОСУДАРСТВЕННЫЙ ИНСТИТУТ МЕЖДУНАРОДНЫХ ОТНОШЕНИЙ

$$
\text { (УНИВЕРСИТЕТ) МИД РФ) }
$$

В статье рассматриваются проблема выбора стратегии развития промышленности России, связанные с ним риски в условиях меняющейся социокультурной реальности. Акцентируется внимание на нецелесообразности имитационной стратегии, которая была предпринята после развала СССР и повлекла за собой усугубление экономической ситуации. Следует принимать во внимание опыт соседних государств, но развиваться исходя из наличия ресурсов своего хозяйства, климата и почвы.

Политические программы, указы, утвержденные главой российского государства, а также существующая геополитическая ситуация свидетельствуют о потенциальной готовно- 
сти нашей страны к переходу на инновационный путь развития, который напрямую связан с модернизацией производства на российских предприятиях. Автором отмечается необходимость пересмотра отношения российского государства и промышленных предпринимателей к технической оснащенности производственных секторов.

В статье приводится анализ двух альтернативных стратегий развития российской промышленности: имитационной и оригинальной. Первая основывается на тотальном заимствовании опыта и знаний передовых стран Запада, вторая основывается на разработке своего проекта развития. Ряд заключений сделан на основе проведенного автором глубинного интервью с руководителем одной из российских компаний в 2015 г.

Сделан вывод о том, что имитационная стратегия не подходит для современной России по ряду причин. Ориентация на инновационный путь развития возможен благодаря разработке оригинальной, гуманистически направленной стратегии: российское государство осознало всю необходимость поддерживать реиндустриализацию промышленности, основанной на модернизации технического сектора производственных площадок в интересах гуманизации российского общества в целом.

Ключевые слова: российская промышленность; инновационный путь развития; риски; имитационная стратегия; оригинальная стратегия, модернизация

\section{ВВЕАЕНИЕ}

C егодня в научно-экспертных и во властно-государственных кругах все более активно обсуждается вопрос срочной необходимости перехода России на инновационный путь развития (XIII Инвестиционный форум ..., 2014: Электронный ресурс), который призван обеспечить конкурентоспособность, в том числе, российской промышленности на мировом рынке. Аанный переход напрямую связан с модернизацией производственных процессов. Но любая модернизация сопряжена с рисками.

В зарубежной и российской науках существует множество определений понятия «риск». Американский экономист - разработчик теории предпринимательства, неопределенности и прибыли Ф. Найт под риском понимал тип неопределенности с возможным неблагоприятным исходом, которую можно измерить с помощью математических и статических методов (Найт, 1994). Французский экономист М. Алле писал о поведении в условиях риска, в ситуации неопределенности (Алле, 1994). Французский социолог М. Фуко видел в риске «определенный дискурс, основу которого составляют идеи неопределенности с возможностью перехода к гаверментальности как новому типу управления, предполагающего сетевые формы безопасности и саморефлексию акторов» (Аапшов, 2014: 11; см.: Фуко, 1996). Немецкий социолог Н. Ауман писал «о решении, в котором... впоследствии придется раскаиваться, если возникнет ущерб, которого надеялись избежать» (Иуман, 1994: 142). То есть риск - это последствия принятого решения. Российский социолог С. А. Кравченко подразумевал под риском «возникновение ситуации с неопределенностью, основанной на дихотомии реальной действительности и возможности: как вероятности наступления объективно неблагоприятного последствия для социальных акторов (индивидуальных или коллективных), так и вероятности обретения выгод и благ, что субъективно воспринимается акторами в контексте определенных ценностных координат, на основании чего осуществляется выбор альтернативы действия» (Кравченко, 2009: 18). Немецкий социолог У. Бек настаивает на введении культурного измерения рисков. Под риском он понимает «систематическое взаимодействие общества с угрозами и опасностями, индуцируемыми и производимыми процессом модернизации как таковым. Риски, в отличие от опасностей прошлых эпох, суть следствия угрожающей мощи модернизации и порождаемых ею чувств неуверенности и страха» (Яницкий, 1996: 14; см. также: Бек, 1994). 
Таким образом, для противостояния рискам модернизации промышленным предприятиям России, чей износ технических фондов и достаточно высокий уровень издержек обращения делает экономику нашей страны неконкурентоспособной по сравнению с мировой, необходимо пересмотреть дальнейшую стратегию своего развития и выбрать между двумя альтернативами: имитационной или оригинальной (Осипов, Кара-Мурза, 2012). Рассмотрим их.

\section{ВОЗМОЖНЫЕ СТРАТЕГИИ РАЗВИТИЯ РОССИЙСКОЙ ПРОМЫШИЕННОСТИ И ИХ РИСКИ}

Аве возможные стратегии были предложены российскими социологами Г. В. Осиповым и С. Г. Кара-Мурзой применительно ко всему российскому обществу. Мы рассмотрим их по отношению к перспективам развития российской промышленности.

Имитационная стратегия развития промышленности предполагает существенное заимствование опыта и знаний передовых стран Запада. Безусловно, освоение и применение данного опыта окажется для современной российской промышленности большим подспорьем.

На наш взгляд, данная имитация таит в себе огромные риски, которые уже проявлялись в реформах 1990-х годов. Об этом писал А. Б. Вебер: «Российские реформаторы 1990-х, избрав имитационный путь модернизации (с ориентацией на американскую модель), сильно переоценили возможности рыночной “самонастройки” и серьезно недооценили присущие рынку дисфункции, значение регулятивной роли государства... масштабы возможных рисков и издержек (Вебер, 2012: 15). Российское государство преследовало цель качественной модернизации как на макроуровне, в масштабе всей страны, так и на микроуровне - в промышленном секторе. «В результате сложилась худшая комбинация из возможных, - подчеркивает А. Б. Вебер, - сочетание неконкурентного, монополизированного, криминального квазирынка с разбухшим коррумпированным бюрократическим аппаратом» (там же). Аанные реформы ослабили Россию, ибо страна, по существу, стала ориентироваться на сырьевое донорство для комфортного и прогрессивного развития современного Запада.

Известно, что попытки копировать привлекательные черты иной цивилизации и перенести их на свою почву зачастую приводят к хаосу и разрушают собственные структуры. Ведь переносятся только верхушечные, видимые плоды имитируемой цивилизации, но которые нежизнеспособны без культурной, философской, даже религиозной основы, на которой они выросли. Такие системы складываются и вырабатываются исторически, поэтому слепая имитация приведет к краху. Так, в свое время французский социолог К. Аеви-Стросс писал: «Трудно представить себе, как одна цивилизация могла бы воспользоваться образом жизни другой, кроме как отказаться быть самой собою. На деле попытки такого переустройства могут привести лишь к двум результатам: либо дезорганизация и крах одной системы - или оригинальный синтез, который ведет, однако, к возникновению третьей системы, не сводимой к двум Аругим» (цит. по: Кара-Мурза, 1996: 6; см.: Lévi-Strauss, 1991: 335).

Риски такого копирования привели к потере идентичности российской промышленности на мировом рынке. По мнению академика Г. В. Осипова и известного российского социолога С. Г. Кара-Мурзы, выбор имитационной стратегии в 1990-е годы был для российского государства тотальной ошибкой, который привел к глубоким повреждениям той матрицы, на которой основывалась и производилась страна как цивилизация (Осипов, Кара-Мурза, 2012: 7). 
Таким образом, интеграция российской промышленности в глобальную систему международного разделения труда по данному сценарию ведет к разрушению ее собственных структур, так как осуществляется перенос лишь верхушечных, видимых плодов имитируемой цивилизации. Аанное разрушение грозит России снижением темпов промышленного роста и сползанием на периферию мирового сообщества.

Оригинальная стратегия основывается на разработке «своего проекта» развития, который предполагает исходить из опыта своего народа, наличия ресурсов своего хозяйства, кдимата и почвы. Но при этом необходимо также изучать опыт других государств.

По нашему мнению, необходимо отметить, что «свой проект», затрагивающий вопрос модернизации производственных площадок, тем не менее связан с процессом передачи передовых стандартов от «лидеров» к «опоздавшим» странам (Балабанова, Грудзинский, Кудряшов, 2002: 18). По мнению Аж.-С. Шина, промышленно развитые «лидеры» полагаются только на свои собственные развивающиеся инновационные способности, в то время как «догоняющие» пытаются сократить свое отставание с помощью трансфера технологий (Shin, 1996: 26). То есть дидирующие страны создают образцы (инновационное оборудование и разработанная на нем технология производства), а отстающие, копируя технологию, пытаются догнать и по возможности усовершенствовать заимствованную инновацию, адаптируя ее к своей реальности. Это явный вызов для социальной и технологической способности российских предпринимателей, рабочих и в первую очередь государства адаптироваться к новому знанию. Аанный процесс заимствования можно считать отправной точкой к переходу на инновационный путь развития.

В свое время в труде «Политика климатического изменения» (2009) американский социолог Э. Гидденс, занимаясь проблематикой рискогенной деятельности человека, влияющей на климат, отметил, что общество при переходе из одного состояния в другое сталкивается с непредвиденными последствиями результата своей деятельности, так как изначально не было к ним подготовлено (Giddens, 2009). Аанный эффект получил название «парадокс Гидденса», под которым имеется в виду то, что «дюди находят для себя трудным с таким же уровнем реальности отнестись к будущему, с каким они относятся к настоящему» (ibid: 2). Таким образом, можно утверждать, что на начальном этапе перехода на новый путь развития российское общество столкнется с проблемой рисков неизвестности. Нам сложно представить себе последствия перехода на инновационный путь развития и России в будущем, несмотря на то что мы осведомлены о необходимости данного перехода и о многих рискогенных проявлениях человеческой деятельности, но порой не принимаем должных усилий по самоизменению.

\section{ПОАИТИЧЕСКИЕ ПРЕАПОСЫАКИ МОАЕРНИЗАЦИИ РОССИЙСКОЙ ПРОМЫШАЕННОСТИ}

Санкции США и стран ЕС поставили Россию перед якобы безальтернативным выбором пути развития. Предполагалось, что наша страна и дальше будет спонсировать их эгоистические амбиции, нивелируя свои политико-экономико-социальные интересы, чтобы в итоге окончательно закрепить за Россией статус сырьевого придатка. Аанная политическая позиция США и стран ЕС вынуждает российскую власть пересмотреть путь дальнейшего развития экономики и ориентироваться на качественную модернизацию существующей российской промышленности, которая лежит в основе оригинальной стратегии. 
Сегодня российский бизнес стал всерьез задумываться о значимых вложениях в модернизацию промышленности на фоне европейско-американской санкционной политико-экономической блокады. Предприниматели ориентированы на приобретение технических и технологических новшеств, в корне меняющих процесс производства и выпуска новых, качественных, конкурентоспособных товаров, так как незначительная модификация существующего оборудования не приносит нужных для сегодняшней российской промышленности результатов. Аанное инвестирование в будущее со стороны предпринимателей планируется осуществлять при поддержке государства (XIII Инвестиционный форум ..., 2014: Электронный ресурс).

По мнению Э. Гидденса, на сегодняшний день «страны утратили большую часть своего прежнего суверенитета, а политики - большинство возможностей влиять на события» (Гидденс, 2004: 25). Это ведет нас к тому, что нужно рефлексировать относительно новых социально-экономических реалий, которые затрагивают экзистенциальные основы существования россиян: ценности, быт, социальный порядок, межличностные отношения, социальные практики, коды сигнификации и т. А. - все, что порождает риски, связанные с выбором из целого ряда возможных альтернатив.

Последствия рисков технической модернизации амбивалентны: кроме благ общество получает и уязвимости. Как считает американский социолог Ч. Перроу, следует ожидать увеличение рисков «нормальных аварий» (Perrow, 1984). Усложняющиеся технологии производства потенциально рискогенны. Таким образом, ускоряющиеся динамики знания содержат в себе риски и уязвимости, к которым необходимо относиться как к данности, подверженной анализу, перед тем как инновационно модернизировать производство (Кравченко, 2010).

Необходимо обратить внимание и на тот факт, что российская экономика завязана на крупных, отчасти старых предприятиях, компаниях, которые, в свою очередь, не склонны к инновациям в силу их бюрократической структуры. Аругим фактором, затрудняющим процесс модернизации производственных площадок, является отсутствие порой у самих предпринимателей реального желания инвестировать в закупку качественного инновационного оборудования (Ковряков, 2010). Согласно исследованиям большинства авторов основным сдерживающим фактором модернизации являются руководители и собственники промышленных предприятий (там же; Тумалев, 2011). Ведь от их выбора будет зависеть модернизация производственных площадок. Таким образом, очевидно, что существует прямая корреляция между модернизацией и процессом выбора (от момента принятия решения о рассмотрении проекта по обновлению оборудования до момента его окончания).

Можно выделить три этапа модернизации промышленного предприятия:

1) принятие решения руководством о необходимости модернизации производства;

2) выбор модернизационного пути: доработка существующего производственного процесса или ориентация на закупку новой линии оборудования;

3) проведение соответствующими подразделениями предприятия конкретных мероприятий для реализации управленческого решения.

После принятия решения начать проект по модернизации производства перед работниками предприятия встает вопрос о способе данного обновления, имеющий потенциально две альтернативы:

1. Оптимизация уже существующего на производственной площадке оборудования подручными средствами (что характерно для краткосрочных проектов). В данном случае существует высокая вероятность получить положительный исход проводимых 
мероприятий, а если результат будет отрицательным, но это не повлияет значимо на доходность и разработку нового продукта промышленного предприятия.

2. Приобретение нового, инновационного, дорогостоящего оборудования (Аля долгосрочных перспектив и выполнения крупных инвестиционных проектов). Это влечет получение высокого социально-экономического статуса предприятия. Аанный подход более рискованный, однако в случае получения положительного результата он принесет больший экономический эффект.

Таким образом, осознание риска принятия неправильного решения может волновать предпринимателя больше, чем потенциальная удача и прибыль от инновационного проекта.

С другой стороны, существует взаимосвязь между уровнем конкуренции и внедрением инноваций на промышленных предприятиях. Если конкуренция не слишком высокая, а финансовые ограничения не совсем жесткие, то можно наблюдать качественное и инновационное обновление технических мощностей на производственных предприятиях. Если же конкуренция высокая, то это негативно влияет на инновации, так как уменьшается прибыль (Aghion et al., 2001).

Инновации претворяются в жизнь главным образом через небольшие молодые компании, финансово ограниченные, которые стараются вырваться и уйти далеко вперед от своих немногочисленных на данный момент конкурентов. Эти инновации чаще всего осуществляются за счет средств самого предприятия, и в случае получения положительного результата исследований новая технология интегрируется в масштабное производство данной компании. После этого крупное предприятие, как правило, покупает әто малое предприятие, и апробированная технология становится результатом инноваций уже крупной корпорации.

\section{КЕЙС-СТАДИ}

Учитывая вышеизложенное, на XVIII Международной выставке химической промышленности и науки «Химия-2015», проходившей с 27 по 30 октября 2015 г. в Москве в ЦВК «Экспоцентр», автором статьи было проведено глубинное интервью с генеральным директором одной российской компании по производству косметических средств по уходу за волосами и кожей. Аанная компания считается абсолютным лидером по выпуску более 1000 видов продуктов в России в своей области.

История данного предприятия началась 14 лет назад, когда группа профессионалов открыла свое дело и закупила китайское использованное оборудование для производства жидких и пастообразных форм. Начало 2000-х годов было тяжелым временем не только для развития уже существовавших деиндустриализированных реформами 1990-х годов предприятий, но и для создания нового, перспективного бизнеса с амбициозными целями.

Как сказал респондент, «на тот момент мало кто из нас задумыъался о явньх и скрытых рисках, о разработке серьезной долгосрочной стратегии. Мь хотели открьть свое дело и стать в будушем лидерами в данной срере. Цель ясна, средства ее достижения определень. Мь начали работать». В те времена конкуренция была не очень развита в косметическом секторе, что также поспособствовало росту данной компании на российском рынке. Позаимствовав у западных коллег и имея разработанные еще в советские годы технологии производства, руководство компании по возможности модернизировало их на находящемся в распоряжении оборудовании. Это привело к существенным материальным әффектам. 
Имитация новшеств принесла свои плоды. Менее пяти лет понадобилось компании для обновления своих технических фондов. В то время было найдено выгодное взаимодействие с европейскими коллегами: «Это было очень хорошее решение на тот момент. Европейские компании, которые используют только инновачионное немецкое качественное оборудование, подготавливали для нас дорогостоящее сырье, а мь в дальнейшем производили конечный продукт из качественных материалов. Тем самымм смогли повысить свой уровень качества конечных товаров и выйти в абсолютные лидеры на своем рынке».

Такая кооперация существовала до начала 2014 г. Этот год стал переломным для компании. Санкции, которые наложили США и страны ЕС, заставили предприятие отойти от имитационной стратегии и начать разрабатывать «свой проект»: «...на тот момент мы находились в переговорах с нашими европейскими коллегами, которые под наши требования к сырью собирались приобрести новую линейку оборудования. Сложив все "за" и "против", мы приняли решение, что выгоднее будет приобрести самим данную линейку оборудования по производству и установить ее на нашем предприятии, чем переплачивать за логистику, хранение, технологию».

Таким образом, через год предприятие установило у себя несколько производственных линий, тем самым увеличив производительность, качество и внедрив инновации в косметическую сферу, перестав быть зависимыми от политики европейских стран. "Аанная модернизачия была рискованным проектом для нас. Нам пришлось самим разрабатьвать технологии обработки и подготовки сырья для дальнейшего его использования. Но, благодаря нашим опьтным технологам и инженерам, мы справились с поставленной задачей. Все это обеспечило нам лидерство в данной промышленности не только на российском, но и на западном рынках. Мьь видим реакиию наших потребителей, они действительно довольны качеством выпускаемой продукиии».

Из интервью видно, что оригинальная стратегия развития приносит существенный экономический, социальный и отчасти политический эффект как для самого предприятия, так и для всей промышленности в целом. Частичная модернизация, основанная на оптимизации существующего производства подручными средствами, дучше подходит для краткосрочных проектов, не ориентированных на инновации. Аля осуществления долгосрочных масштабных целей необходимо рисковать, разрабатывать «свой проект», чтобы в перспективе иметь свободу действий в плане выбора своего пути развития в масштабах как одного предприятия, так и всей страны.

\section{ЗАКАЮЧЕНИЕ}

Таким образом, можно сделать вывод, что имитационная стратегия как новый путь развития не подходит для современной России по ряду причин: реформы 1990-х годов показали всю несостоятельность данного подхода ввиду несоответствия историческому контексту развития нашей страны, изменяющимся социокультурным реалиям, слабому развитию промышленности. Ориентация России на инновационный путь развития возможна благодаря разработке оригинальной, гуманистически направленной стратегии: российское государство осознало всю необходимость поддерживать реиндустриализацию промышленности, основанной на модернизации технического сектора производственных площадок в интересах гуманизации российского общества в целом. Модернизация производственных процессов позволит создавать качественный, инновационный, конкурентоспособный продукт, который принесет больший 
экономический и гуманистический эффект как для самих промышленных предприятий, так и для всей страны в целом.

\section{СПИСОК АИТЕРАТУРЫ}

Алле, М. (1994) Поведение рационального человека в условиях риска: критика постулатов и аксиом американской школы / пер. с фр. И. А. Егорова // Thesis. № 5. С. 217-241.

Балабанова, Е. С., Грудзинский А. О., Кудряшов, Ю. Г. (2002) Модернизация предприятий: факторы и направления // Социологические исследования. № 6. С. 18-28.

Бек, У. (1994) От индустриального общества к обществу риска / пер. с англ. А. А. Ковалева // Thesis. № 5. C. 161-168.

Вебер, А. Б. (2012) Россия перед инновационным выбором [Электронный ресурс]// Свободная мысль. № 5-6. С. 12-25. URL: http://intelros.ru/pdf/svobodnay_misl/2012_5_6/2.pdf [архивировано в WebCite] (дата обращения: 30.03.2015).

Гидденс, Э. (2004) Ускользающий мир: как глобализация меняет нашу жизнь / пер с англ. М. А. Коробочкина. М. : Весь мир. 116 с.

Кара-Мурза, С. Г. (1996) Евроцентризм: скрытая идеология перестройки. М. : СИМС. 143 с.

Ковряков, А. В. (2010) Мотивационные аспекты модернизации российской экономики // Проблемы системной модернизации экономики России: социально-политический, финансовоэкономический и экологический аспекты : сб. науч. статей. Вып. 9/ под общ. ред. В. В. Тумалева. СПб. : НОУ ВПО «Институт бизнеса и права». 558 с. С. 23-29.

Кравченко, С. А. (2009) Риски грядущей модернизации страны: нужны социологи-рискологи // Вестник МГИМО-Университета. № 6. С. 15-26.

Кравченко, С. А. (2010) Аинамика современных социальных реалий: инновационные подходы // Социологические исследования. № 10. С. 14-25.

Аапшов, В. А. (2014) Теоретические основы социологического исследования социальных рисков // Актуальные вопросы инновационной экономики. № 6. С. 5-25.

Ауман, Н. (1994) Понятие риска / пер. с нем. А. Ф. Филиппова // Thesis. № 5. С. 135-160.

Найт, Ф. (1994) Понятия риска и неопределенности : пер. с англ. С. А. Афонцева // Thesis. № 5 . С. 12-28.

Осипов, Г. В., Кара-Мурза, С. Г. (2012) Общество знания: История модернизации на Западе и в СССР. M. : URSS ; Аиброком. 368 с.

Тумалев, А. В. (2011) Традиции, инновации и причины неудач инновации // Россия: потенциал инновационного развития : сб. науч. ст. аспирантов и студентов. Вып. 10 / под общ. ред. В. В. Тумалева. СПб. : НОУ ВПО «Институт бизнеса и права». 236 с. С. 32-37.

Фуко, М. (1996) Археология знания / пер. с фр. С. Митина, А. Стасова ; общ. ред. Б. Аевченко. Киев : Ника-Центр. 208 с.

Яницкий, О. Н. (1996) Экологическое движение в России : критический анализ / Рос. акад. наук, Ин-т социологии. М. : Б. и. 216 с.

XIII Инвестиционный форум «Сочи-2014» (2014) [Электронный ресурс] // Правительство России. 19 сентября. URL: http://government.ru/news/14835/ [архивировано в WebCite] (дата обращения: 16.10.2014).

Aghion, P., Harris, C., Howitt, P., Vickers, J. (2001) Competition, imitation and growth with stepby-step innovation // The Review of Economic Studies. Vol. 68. No. 3. P. 467-492.

Giddens, A. (2009) The politics of climate change. Cambridge ; Malden, MA : Polity Press. viii, 264 p.

Lévi-Strauss, C. (1991) Antropologia estructural: Mito, sociedad, humanidades. Mexico : Siglo XXI Eds. 352 p.

Perrow, C. (1984) Normal accidents: Living with high-risk technologies. N. Y. : Basic Books. x, 386 p.

Shin, J.-S. (1996) The economics of the latecomers: Catching-up, technology transfer, and institutions in Germany, Japan, and South Korea. L. ; N. Y. : Routledge. xiv, 214 p. 
RISKS OF CHOOSING A DEVELOPMENT STRATEGY FOR RUSSIAN INDUSTRY

E. A. PANFILOVA

(Moscow State INSTITUTE Of INTERNATIONAL RELATIONS (UNIVERSITY))

The article examines the problem of choosing a development strategy for Russian industry and the associated risks under the conditions of a changing socio-cultural reality. Specifically, we focus on the impractical simulation strategy, which was chosen by government agencies after the collapse of the Soviet Union, thus contributing to further aggravation of the economic situation. We argue that although the experience of the neighboring countries should be taken into account, the main foundations for further development are to be found in the available economic, climatic and soil resources.

Political programs, presidential decrees, as well as the current geopolitical situation prove that our society is potentially ready to pursue the innovative path of development, which is directly related to modernizing production lines at Russian industrial enterprises. Both state agencies and industrial entrepreneurs have to review their attitudes to the technical equipment in the manufacturing sectors.

The article provides an analysis of two alternative strategies of the development of Russian industry: the simulative one and the original one. The simulative strategy involves a total borrowing of the experience and knowledge from more advanced economies of the West, while the original development strategy intends to pursue a genuine project. Some of the conclusions we arrive at in the article are based on an in-depth interview with a top manager of a Russian company conducted in 2015.

We conclude that the simulation strategy is not suitable for modern Russia due to a number of reasons. A focus on the innovative way of development is possible by means of an original and humanismdriven strategy. The Russian government has realized the need for reindustrialization of the economy through modernizing the technological sector of production facilities. Ultimately, this will help in making Russian society in general more humane.

Keywords: Russian industry; innovative path of development; risks; simulation strategy; original strategy; modernization

\section{REFERENCES}

Allais, M. (1994) Povedenie ratsional'nogo cheloveka v usloviiakh riska: kritika postulatov i aksiom amerikanskoi shkoly [The behavior of rational man facing risk: Criticism of the postulates and axioms of the American school]/ transl. from French by I. A. Egorov. Thesis, no. 5, pp. 217-241. (In Russ.).

Balabanova, E. S., Grudzinskii, A. O. and Kudriashov, Yu. G. (2002) Modernizatsia predpriiatii: faktory i napravlenia [Modernisation of enterprises: Factors and directions]. Sotsiologicheskie issledovaniia, no. 6, pp. 18-28. (In Russ.).

Beck, W. (1994) Ot industrial'nogo obshchestva k obshchestvu riska [From industrial society to the risk society]/ transl. from English by A. D. Kovalev. Thesis, no. 5, pp. 161-168. (In Russ.).

Veber, A. B. (2012) Rossiia pered innovatsionnym vyborom [Russia in front of the innovative choice]. Svobodnaia mysl', no. 5-6, pp. 12-25. [online] Available at: http://intelros.ru/pdf/svobodnay_misl/2012_5_6/2.pdf [archived in WebCite] (accessed 30.03.2015). (In Russ.).

Giddens, A. (2004) Uskol'zaiushchii mir: kak globalizatsiia meniaet nashu zhizn' [Runaway world: How globalization is reshaping our lives]/ transl. from English by M. L. Korobochkin. Moscow, Ves' mir Publ. 116 p. (In Russ.).

Kara-Murza, S. G. (1996) Evrotsentrizm: skrytaia ideologiia perestroiki [Eurocentrism: Concealed ideology of perestroika]. Moscow, SIMS Publ. 143 p. (In Russ.).

Kovriakov, D. V. (2010) Motivatsionnye aspekty modernizatsii rossiiskoi ekonomiki [Motivational aspects of modernization of Russia's economy]. In: Problemy sistemnoi modernizatsii ekonomiki Rossii: sotsial'no-politicheskii, finansovo-ekonomicheskii i ekologicheskii aspekty [Issues of systemic modernization of Russia's economy: Sociopolitical, financial, economic and environmental aspects]: A collection of articles. Issue 9. / ed. by V. V. Tumalev. St. Petersburg, Institute of Business and Law Publ. 558 p. Pp. 23-29. (In Russ.). 
Kravchenko, S. A. (2009) Riski griadushchei modernizatsii strany: nuzhny sotsiologi-riskologi [Risks of future modernization of the country: We need sociologists-riskologists]. Vestnik MGIMOUniversiteta, no. 6, pp. 15-26. (In Russ.).

Kravchenko, S. A. (2010) Dinamika sovremennykh sotsial'nykh realii: innovatsionnye podkhody [The dynamics of contemporary social realities: innovative approaches]. Sotsiologicheskie issledovania, no. 10, pp. 14-25. (In Russ.).

Lapshov, V. A. (2014) Teoreticheskie osnovy sotsiologicheskogo issledovaniia sotsial'nykh riskov [Theoretical foundations of the sociological study of social risks]. Aktual' nye voprosy innovatsionno $i$ ekonomiki, no. 6, pp. 5-25. (In Russ.).

Luhmann, N. (1994) Poniatie riska [The concept of risk]/ transl. from German by A. F. Filippov. Thesis, no. 5, pp. 135-160. (In Russ.).

Knight, F. (1994) Poniatia riska i neopredelennosti [The meaning of risk and uncertainty]/ transl. from English by S. A. Afontsev. Thesis, no. 5, pp. 12-28. (In Russ.).

Osipov, G. V. and Kara-Murza, S. G. (2012) Obshchestvo znania: Istoria modernizatsii na Zapade $i v$ SSSR [Knowledge society: The history of modernization in the West and in the USSR]. Moscow, URSS Publ. ; Librokom Publ. 368 p. (In Russ.).

Tumalev, A. V. (2011) Traditsii, innovatsii, prichiny neudach innovatsii [Traditions, innovations and reasons for the failure of innovations]. In: Rossia: potentsial innovatsionnogo razvitia [Russia: A potential for innovative development]: A collection of articles by postgraduate and undergraduate students. Vol. 10 / ed. by V. V. Tumalev. St. Petersburg, Institute of Business and Law Publ. 236 p. Pp. 32-37. (In Russ.).

Foucault, M. (1996) Arkbeologia znaniia [The archaeology of knowledge]/ transl. from French by S. Mitin and D. Stasov; ed. by B. Levchenko. Kiev, Nika-Tsentr Publ. 208 p. (In Russ.).

Yanitskii, O. N. (1996) Ekologicheskoe dvizhenie v Rossii : kriticheskii analiz [Ecological movement in Russia: A critical analysis] / Russian Academy of Sciences, Institute of Sociology. Moscow, s. n. 216 p. (In Russ.).

XIII Investitsionnyi forum: «Sochi-2014» [The 13th Investment Forum: "Sochi-2014"] (2014) Pravitel'stvo Rossii, September 19. [online] Available at: http://government.ru/news/14835/ [archived in WebCite] (accessed 16.10.2014). (In Russ.).

Aghion, P., Harris, C., Howitt, P. and Vickers, J. (2001) Competition, imitation and growth with step-by-step innovation. The Review of Economic Studies, vol. 68, no. 3, pp. 467-492.

Giddens, A. (2009) The politics of climate change. Cambridge ; Malden, MA, Polity Press. viii, 264 p.

Lévi-Strauss, C. (1991) Antropologia estructural: Mito, sociedad, bumanidades. Mexico, Siglo XXI Eds. 352 p.

Perrow, C. (1984) Normal accidents: Living with high-risk technologies. New York, Basic Books. $\mathrm{x}, 386 \mathrm{p}$.

Shin, J.-S. (1996) The economics of the latecomers: Catching-up, technology transfer, and institutions in Germany, Japan, and South Korea. London ; New York, Routledge. xiv, 214 p.

Submission date: 7.12 .2015 .

Панфилова Евгения Аркадьевна - аспирант кафедры социологии Московского государственного института международных отношений (Университет) МИА РФ. Адрес: 119454, Россия, г. Москва, пр. Вернадского, д. 76. Тел.: + 7 (495) 434-94-26. Эл. адрес: aires_lynx@mail.ru. Научный руководитель - д-р социол. наук, проф. А. Н. Носкова.

Panfilova Evgeniya Arkadievna, Postgraduate Student, Department of Sociology, Moscow State Institute of International Relations (University) of Ministry of Foreign Affairs of the RF. Postal address: 76 Vernadskogo Pr., 119454 Moscow, Russian Federation. Tel.: + 7 (495) 434-94-26. E-mail: aires_lynx@mail.ru. Research advisor: A. N. Noskova, Doctor of Sociology, Professor. 